\title{
Effect of local weather on butterfly flight behaviour, movement, and colonization: significance for dispersal under climate change
}

\author{
Anouk Cormont • Agnieszka H. Malinowska • Olga Kostenko • \\ Victoria Radchuk • Lia Hemerik • Michiel F. WallisDeVries • \\ Jana Verboom
}

Received: 15 October 2009/Accepted: 9 December 2010/Published online: 24 December 2010

(C) The Author(s) 2010. This article is published with open access at Springerlink.com

\begin{abstract}
Recent climate change is recognized as a main cause of shifts in geographical distributions of species. The impacts of climate change may be aggravated by habitat fragmentation, causing regional or large scale extinctions. However, we propose that climate change also may diminish the effects of fragmentation by enhancing flight behaviour and dispersal of ectothermic species like butterflies. We show that under weather conditions associated with anticipated climate change, behavioural components of dispersal of butterflies are enhanced, and colonization frequencies increase. In a field study, we recorded flight behaviour and mobility of four butterfly species: two habitat generalists (Coenonympha pamphilus; Maniola jurtina) and two specialists (Melitaea athalia; Plebejus argus), under different weather conditions. Flying bout duration generally increased with temperature and decreased with cloudiness. Proportion of time spent flying
\end{abstract}

A. Cormont $(\bowtie) \cdot$ J. Verboom

Alterra, Wageningen University and Research Centre, P.O. Box 47,

6700 AA Wageningen, The Netherlands

e-mail: anouk.cormont@wur.nl

A. Cormont

Land Use Planning Group, Wageningen University, P.O. Box 47,

6700 AA Wageningen, The Netherlands

A. H. Malinowska · O. Kostenko · V. Radchuk

Environmental Systems Analysis Group, Wageningen University, P.O. Box 47,

6700 AA Wageningen, The Netherlands

L. Hemerik

Biometris, Department of Mathematical and Statistical Methods, Wageningen University,

P.O. Box 100, 6700 AA Wageningen, The Netherlands

M. F. WallisDeVries

De Vlinderstichting/Dutch Butterfly Conservation, P.O. Box 506,

6700 AM Wageningen, The Netherlands

M. F. WallisDeVries

Laboratory of Entomology, Wageningen University, P.O. Box 8031,

$6700 \mathrm{EH}$ Wageningen, The Netherlands 
decreased with cloudiness. Net displacement generally increased with temperature. When butterflies fly longer, start flying more readily and fly over longer distances, we expect dispersal propensity to increase. Monitoring data showed that colonization frequencies moreover increased with temperature and radiation and decreased with cloudiness. Increased dispersal propensity at local scale might therefore lower the impact of habitat fragmentation on the distribution at a regional scale. Synergetic effects of climate change and habitat fragmentation on population dynamics and species distributions might therefore appear to be more complex than previously assumed.

Keywords Bout duration - Cloudiness - Colonization probability · Habitat fragmentation . Lepidoptera · Net displacement · Proportion of time spent flying · Radiation ·

Temperature $\cdot$ Weather

\section{Introduction}

Climate change causes shifts in geographical distributions of species (Parmesan and Yohe 2003; Root et al. 2003). Such shifts are considered to be the result of (meta)population extinction at the equatorial range boundary, and poleward colonization in regions where climatic conditions have newly become suitable (Opdam and Wascher 2004). Parmesan and Yohe (2003) reported shifts in the direction of the predicted climate change for $81 \%$ of 460 species of diverse taxa. Warren et al. (2001) expected butterfly species approaching their northern climatic range margins in Britain to respond positively to climate warming over the past decennia. Yet, only a quarter of these species increased their area of geographical distribution, supposedly because positive responses to climate warming were outweighed by negative effects of habitat fragmentation, especially for less mobile specialists (Travis 2003). Other empirical studies (Anderson et al. 2009; Devictor et al. 2008; Schwartz et al. 2001) confirm for other species groups that a response to climate change may be hampered by habitat fragmentation.

Habitat availability and spatial cohesion of habitat patterns play a crucial role in the persistence of species under global temperature rise: below a critical threshold the expansion of ranges will be blocked and species can rapidly become extinct (Opdam and Wascher 2004; Travis 2003). Increased frequency of extreme weather events will moreover cause overall range contraction, especially with relatively low spatial cohesion (Opdam and Wascher 2004).

However, these statements on detrimental effects of climate change in fragmented habitat assume that habitat availability, habitat use and interpatch movement do not vary under the expected climate change regime. Thomas et al. (2001) show that such assumptions may not be realistic, as they found a significant broadening of the range of habitats used by Silver-spotted skipper, Hesperia comma L., spreading into north-facing hill slope habitats that were previously climatically not suitable. We suggest that for butterflies, interpatch movement can be facilitated if dispersal propensity will be enhanced by climate change. Butterfly behaviour responds to weather conditions, as is shown by previous studies (Brattstrom et al. 2008; Brown 1970; Clench 1966; Douwes 1976; Shreeve 1984). These studies, however, focus on single weather parameters, species or types of behaviour, and do no elucidate the link between weather, behaviour, and dispersal.

In practice, butterfly dispersal is difficult to measure. Butterflies are not robust enough to carry biotelemetry transmitters (Van Dyck and Baguette 2005). In this paper we therefore use a proxy for dispersal, and assume that dispersal propensity will increase as 
individuals of species fly over longer bout durations, increase their tendency to start flying, spend more time flying, and fly over longer distances (cf. Morales and Ellner 2002; Nathan et al. 2008; Van Dyck and Baguette 2005). We recorded flight behaviour and mobility of four butterfly species under variable weather conditions. Because dispersal differs widely between species, we consider two habitat generalist and two specialist species. Next, we tested whether dispersal propensities and patch colonization probability are indeed enhanced by the favourable weather conditions emerging from the field study. To this effect we correlated data on annual colonization frequencies from monitoring transects counts to weather conditions.

\section{Methods}

Study area

The fieldwork was carried out in National Park "De Hoge Veluwe" in the centre of the Netherlands (Fig. $1 ; 52^{\circ} 02-52^{\circ} 07^{\prime} \mathrm{N} ; 5^{\circ} 47-5^{\circ} 52^{\prime} \mathrm{E}$; elevation about $40 \mathrm{~m}$ asl.) during the summers of 2006 and 2007. The total area of the park is 5,500 ha, including 2,500 ha of heathland and inland dunes.

\section{Studied species}

Four butterfly species were studied: the habitat generalists Small heath, Coenonympha pamphilus L. and Meadow brown, Maniola jurtina L., and specialists Heath fritillary, Melitaea athalia Rott. and Silver-studded blue, Plebejus argus L.

Coenonympha pamphilus is a common resident in the Netherlands (Bos et al. 2006). It lives in open mosaic habitats such as grasslands, dunes, roadside verges, and gardens (Van Swaay 2003). The species is bivoltine (first flight period from May 20-July 20, and July 29-September 5 for the second generation, on average) and not very mobile. Only minor range shifts are expected in response to climate change for C. pamphilus (Settele et al. 2008).

M. jurtina is a common resident in the Netherlands. It lives in a variety of rough grasslands and open woodlands. The butterfly is univoltine (average flight period: June 26 - August 15) and quite mobile. In response to climate change, only minor range shifts are anticipated for M. jurtina (Settele et al. 2008).

Melitaea athalia has become a very rare resident in the Netherlands, nowadays restricted to the Veluwe area. Suitable habitats are sunny, open places in forests such as woodland edges, newly felled woodlands and clearings in coppice. The species is univoltine (average flight period: June 16-July 15) and sedentary. Still, in response to climate change, M. athalia is expected to show northward range expansion (Berry et al. 2007; Hill et al. 2002).

Plebejus argus is a scarce resident in the Netherlands, classified as vulnerable on the Dutch Red List. $P$. argus lives both in dry and wet heathlands with sparse vegetation and patches of bare ground. It is a univoltine species (average flight period: June 26-August 5) and rather sedentary. In response to climate change, $P$. argus is expected to show northward range expansion (Berry et al. 2007; Hill et al. 2002). We studied mostly male individuals of $P$. argus, because the inconspicuously coloured females were more difficult to track. 


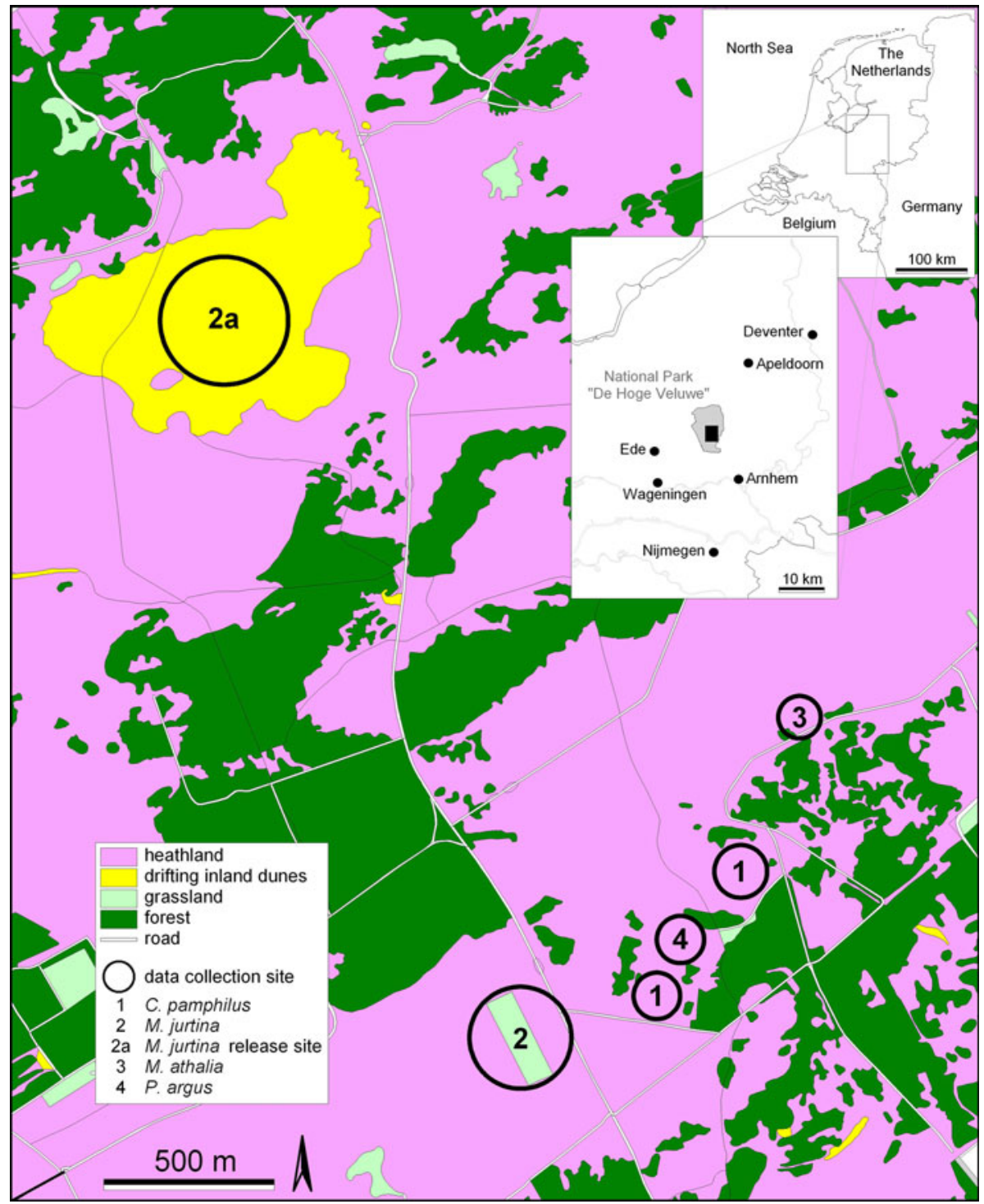

Fig. 1 Study area within National Park "De Hoge Veluwe" indicating location of data collection sites per species. Inset shows location of the National Park in the Netherlands

Measured weather variables

Climate is often defined as meteorological conditions (wind, humidity, temperature, cloudiness, precipitation, etc.) over long periods, usually 30-50 years (Barry and Chorley 2003). Effects of climate or climate change should therefore be studied with data gathered over long time spans. Weather is the short-term manifestation of meteorological conditions and changes can therefore be observed within the time frame of a field study. We considered four weather variables that influence activity and dispersal (Clench 1966; 
Douwes 1976; Mitikka et al. 2008; Shreeve 1984): ambient temperature (measured with mercury thermometer placed in the shade; in Celsius, ${ }^{\circ} \mathrm{C}$ ), cloudiness (observer's estimation in percentage cover), wind speed (observer's estimation or measured with anemometer; in Beaufort, Bft), and a proxy for solar radiation. The solar radiation proxy was determined by placing a black and white surface in the sun, and measuring the surface temperatures using a portable infrared thermometer. The difference in temperature between the surfaces is a measure of temperature gain by solar radiation (Van Dyck and Matthysen 1998).

Data collection

The fieldwork was conducted in 2006 and 2007 from mid June until mid August. Observations took place between 10.00 and $17.00 \mathrm{~h}$. A total of 207 tracks (114 in 2007), were recorded for the four species: C. pamphilus 106 tracks (73 in 2007); M. jurtina 55 (22); M. athalia 23 (12); and $P$. argus 23 (7). For each track, a butterfly was caught in a net and its sex was determined. The butterfly was coded with permanent marker on the underside of both hindwings. After release from the net, we allowed the butterfly to calm down before behavioural observations started. We followed the butterfly at a distance of 2-5 m. To each activity, we assigned one of the potential behaviour types: flying, nectaring, resting (with wings closed), basking (with wings opened perpendicular to the sun), testing [the abdominal and antennal exploration of a host plant associated with ovipositing, (Root and Kareiva 1984)], or ovipositing. The time spent in each of the activities was recorded. Each individual was followed for $30 \mathrm{~min}$, or until lost from sight. We used a GPS device (2006: Garmin eTrexVenture ${ }^{\mathrm{TM}}$; 2007: HP iPAQ hw6500) to record the track locations. The four studied species of butterflies were tracked within their habitat (see Fig. 1). In addition, in 2007 we conducted release experiments for M. jurtina in an area of drifting inland dunes, that we considered as non-habitat to this species. In this hostile environment, we tracked the behaviour and mobility of 8 individuals as if they were moving between habitat patches. The release site was located at a distance of approximately $2000 \mathrm{~m}$ from the catching site, which is much further than the perceptual range of individuals (100-150 m according to Conradt et al. (2001)). We used only M. jurtina for the release experiments, because it was most abundant, not endangered, and easiest to track in an open, windy environment. Each individual was tracked only once.

At the beginning of each track, we measured temperature, wind speed and cloud cover. At the end of the observation we re-measured temperature, wind speed, and determined the temperature difference between the black and white surfaces (further referred to as radiation; Table 1). In the Netherlands, the summer of 2006 was hot and dry in June and July (July was on average the hottest month since the beginning of the records by the Royal Netherlands Meteorological Institute in 1706), while August was relatively chilly and rainy. After a very mild spring, the weather during the summer of 2007 was changeable and rainy.

Table 1 Means (standard deviation) of temperature, radiation, cloudiness, and wind speed during the fieldwork in 2006 and 2007

\begin{tabular}{lllll}
\hline Year & $\begin{array}{l}\text { Temperature } \\
\left({ }^{\circ} \mathrm{C}\right)\end{array}$ & $\begin{array}{l}\text { Radiation } \\
\left({ }^{\circ} \mathrm{C}\right)\end{array}$ & $\begin{array}{l}\text { Cloudiness } \\
(\%)\end{array}$ & $\begin{array}{l}\text { Wind speed } \\
(\mathrm{Bft})\end{array}$ \\
\hline 2006 & $26.5(4.7)$ & $17.6(8.3)$ & $47.0(39.5)$ & $3.3(1.7)$ \\
2007 & $19.5(3.4)$ & $16.3(9.1)$ & $52.4(28.0)$ & $3.6(2.3)$ \\
\hline
\end{tabular}


Survival analysis

The field data of 2006 and 2007 together were used to assess the influence of the measured weather variables on the observed duration of flying bouts [i.e. the time of uninterrupted flight behaviour, (Haccou and Meelis 1992)] and non-flying bouts (i.e. nectaring, resting, basking, testing, or ovipositing) per species. We summed the durations of all consecutive non-flight behaviour as a single non-flying bout. The nature of the data (i.e. 'time-to-event' data with censors) required the application of survival analysis (Kleinbaum and Klein 2005). Censoring occurred when the observation time elapsed or when the butterfly was lost from sight. Cox's proportional hazards model was used to analyze which weather variables affected the tendency of a butterfly to terminate a bout. It was assumed that butterflies have a basic tendency to stop a specific behaviour (baseline hazard). Therefore, the observed hazard rate (the observed tendency to stop a specific behaviour) is the product of the baseline hazard and a factor that gives the joint effect of all covariates (here, weather variables). The general form of the model is (Haccou and Hemerik 1985; Kalbfleisch and Prentice 2002):

$$
h\left(t ; x_{i}, \ldots, x_{p}\right)=h_{0}(t) \cdot \exp \left(\sum_{i=1}^{p} \beta_{i} x_{i}\right) \quad \text { [in probability per time unit }
$$

where $h\left(t ; x_{i}, \ldots, x_{p}\right)$ represents the observed hazard rate at time $t$ with $p$ fixed covariates having values $x_{i}, \ldots, x_{p} ; h_{0}(t)$ is the baseline hazard; $t$ is the time since the last bout termination; and $x_{i}$ is the vector of covariates. The baseline hazard is multiplied by an exponential function that expresses the multiplicative effect of the 1 to $p$ covariates, multiplied by the corresponding regression parameters $\beta_{i}$. If a particular covariate $x_{i}$ does not influence the observed hazard rate, then $\beta_{i}$ does not differ significantly from 0 . The estimates for the regression coefficients are used to compute a hazard ratio (HR), which describes the effect of the covariate (Kalbfleisch and Prentice 2002). Its significance is assessed with a $Z$ score. Covariates used in the analysis were coded as categorical since the measurements were unevenly spread over the ranges: temperature $\left({ }^{\circ} \mathrm{C} ; T\right)$, radiation $\left({ }^{\circ} \mathrm{C}\right.$; $R$ ), cloudiness (\% cloud cover; $C$ ), wind speed $(\mathrm{m} / \mathrm{s} ; W)$, gender $(G$; male versus baseline female), and year ( $Y$; 2007 versus baseline 2006; representing unmeasured factors changing between years, e.g. food supply). Weather variables were clustered into 'low', 'intermediate', and 'high' categories to distinguish optimum or unidirectional effects of weather variables on the duration of bouts (Table 2). We based the clustering of covariates on Kaplan-Meier plots. A Kaplan-Meier survival curve is a step function that decreases from 1 (all individuals are still flying at time $t$ ) toward a minimum value $>0$ due to termination of flying bouts. Kaplan-Meier survival curves should be parallel for all covariate categories, i.e. should not cross (Kalbfleisch and Prentice 2002), in order to be able to assume proportionality estimating the effect size in Cox model(s). We plotted Kaplan-Meier survival curves for flying bouts for all covariate values separately, to see under what values curves do not cross (for an example see Appendix Fig. 4). Clustering was subsequently based on best Kaplan-Meier plot appearance. Next, we tested for pairwise differences in behavioural response under low, intermediate and high weather categories. The effects of single weather variables were estimated simultaneously with other weather variables. We used R 2.7.0 software (Ihaka and Gentleman 1996) to perform the survival analysis. For $P$. argus, temperature, cloudiness, and wind speed were highly correlated, and differed strongly between years (see Appendix Table 8). Therefore, only radiation was used in the analysis, together with gender and year. 
Table 2 Clustering of weather variables into 'low', 'intermediate', and 'high' categories per species, resulting from Kaplan-Meier survival curves for flying bouts

\begin{tabular}{llllll}
\hline Weather variable & Category & $C$. pamphilus & M. jurtina & M. athalia & $P$. argus \\
\hline Temperature $\left(T\right.$; in $\left.{ }^{\circ} \mathrm{C}\right)$ & Low & $T \leq 19.5$ & $T \leq 20$ & $T \leq 14$ & $T \leq 22$ \\
& Intermediate & $19.5<T \leq 25.5$ & $20<T \leq 31$ & $14<T \leq 25$ & $22<T \leq 28$ \\
& High & $T>25.5$ & $T>31$ & $T>25$ & $T>28$ \\
Radiation $\left(R\right.$; in $\left.{ }^{\circ} \mathrm{C}\right)$ & Low & $R \leq 12$ & $R \leq 10$ & $R \leq 14$ & $R \leq 17$ \\
& Intermediate & $12<R \leq 28$ & $10<R \leq 20$ & $14<R \leq 31$ & $17<R \leq 20$ \\
& High & $R>28$ & $R>20$ & $R>31$ & $R>20$ \\
Cloudiness $(C$; in \%) & Low & $C \leq 15$ & $C \leq 15$ & $C \leq 25$ & $C=0$ \\
& Intermediate & $15<C \leq 60$ & $15<C \leq 70$ & $25<C \leq 70$ & $0<C \leq 20$ \\
& High & $C>60$ & $C>70$ & $C>70$ & $C>20$ \\
Wind speed $(W$; in Bft) & Low & $W \leq 1$ & $W \leq 2$ & $W \leq 3$ & $W \leq 2$ \\
& Intermediate & $1<W \leq 2$ & $2<W \leq 4$ & $3<W \leq 4$ & $2<W \leq 3$ \\
& High & $W>2$ & $W>4$ & $W>4$ & $W>3$ \\
\hline
\end{tabular}

Time budget analysis

For each tracked individual, we calculated the proportion of time devoted to a certain behaviour. We tested for differences between weather categories in proportion of time spent flying as opposed to non-flight behaviour, using Wilcoxon rank sum test $(W)$ in $\mathrm{R}$ 2.7.0. Ten individuals devoting their total tracked time to flight behaviour, were excluded from the analysis, because these individuals were lost from sight within the first recorded bout. Time budget analysis (Miron et al. 1992) is complementary to survival analysis, since possible changes in bout duration are compensated by changes in occurrence of these bouts.

\section{Spatial analysis}

Spatial coordinates were recorded at a constant time interval (2006: $10 \mathrm{~s}$; 2007: $1 \mathrm{~s}$ ) by the GPS device. Coordinates derived from the Garmin eTrexVenture ${ }^{\mathrm{TM}}$ were transformed into.shp files using GPS2Shape software (Jochem 2006). Successive points were connected with straight lines and are further referred to as steps. For each individual, we analysed the total pathway, determining tortuosity as the standard deviation in turning angle in proportion to a full circle (in radians divided by $2 \pi$ ) and the net displacement of the pathway (i.e. the distance between the track starting and ending points; in metres). The effects of weather variables on tortuosity and net displacement were tested using regression analysis with generalized linear models in $\mathrm{R}$ 2.7.0.

In addition, we compared the tortuosity and net displacement of the pathways of released individuals of $M$. jurtina with pathway characteristics of individuals tracked within their habitat using Wilcoxon rank sum test $(W)$ in $\mathrm{R}$ 2.7.0. The effects of weather variables and presence of habitat on tortuosity and net displacement were tested using regression analysis with generalized linear models in R 2.7.0 and Akaike's information criterion for model selection (Burnham and Anderson 2002). 
Colonization frequency

Data on colonization frequency were obtained from the Dutch Butterfly Monitoring Scheme monitoring (Van Swaay et al. 2008), with standardized transect counts over the period 1990-2008. The total number of transects where the study species were sighted strongly differed between species: 452 for C. pamphilus, 737 for M. jurtina, 22 for $M$. athalia, and 155 for $P$. argus. Because of the small sample size, we excluded $M$. athalia from this analysis. A colonization event for a particular species was defined as a sighting of at least one individual after 2 years of absence. Absences were only counted as such when sufficient counts were carried out during the flight period. Relative colonization frequencies were then calculated on an annual basis between 1992 and 2008 as the number of transects with colonizations relative to the total number of actively counted transects where the species might be expected, i.e. where it had been sighted in the period 1990-2008. Data on daily temperature (mean and maximum; in ${ }^{\circ} \mathrm{C}$ ), radiation (in $\mathrm{J} / \mathrm{cm}^{2}$, converted to temperature differences in ${ }^{\circ} \mathrm{C}$ ), cloudiness (in octants, converted to \%), and wind speed (in $\mathrm{m} / \mathrm{s}$, converted to Bft) were obtained from the Royal Netherlands Meteorological Institute (www.knmi.nl) for the flight periods of the three species. For each year, we averaged the weather variables over the flight periods. The effects of average weather variables on colonization frequencies were tested using regression analysis with generalized linear models in $\mathrm{R}$ 2.7.0. We corrected for possible effects of density dependence by taking national population numbers (as indices) into consideration. The effect of both the current and the previous year's weather was included (see also Roy et al. 2001). The current year's weather is assumed to affect dispersal propensity of individuals that will subsequently be sighted on a transect, newly colonized due to their dispersal. The previous year's weather is assumed to affect dispersal propensity of individuals that will subsequently reproduce on a transect, newly colonized after their dispersal; their offspring will be sighted in the following year.

\section{Results}

Survival analysis

Results of the survival analysis are on tendencies to stop flying (behaviour type: flying; Table 3) or to start flying (behaviour type non-flying; Table 4). A greater tendency to stop flying implies shorter flight duration. The duration of flying bouts extended with high temperatures $(C$. pamphilus, $P=0.01 ; M$. jurtina, $P=0.013)$. Intermediate and high radiation extended duration of flying bouts for $P$. argus $(P=0.011, P=0.002$ resp. $)$, but high radiation showed negative effects on the duration of flying bouts for $C$. pamphilus $(P=0.01)$. Intermediate and high cloudiness reduced the duration of flying bouts (M. athalia, $P=0.002, P=0.001$ resp.; $C$. pamphilus, $P=0.017$ for high cloudiness only). Intermediate and high wind speed also showed negative effects on the duration of flying bouts $(C$. pamphilus, $P=0.006, P=0.0004$ resp.) In general, males exhibited longer flights than females $(C$. pamphilus, $P=0.014)$ and in 2007 , flight durations were longer ( $M$. jurtina, $P=0.005 ; M$. athalia, $P=0.025)$.

The tendency to start flying was enhanced at intermediate and high temperatures (M. jurtina, $P=0.018, P=0.039$ resp.), and at intermediate and high radiation (C. pamphilus, $P=0.004$; $M$. athalia, $P=0.004, P=0.002$ resp.). Intermediate and high cloudiness showed negative effects on this tendency for $C$. pamphilus $(P=0.026$; 
Table 3 Results survival analysis for flight behaviour based on multivariate Cox's proportional hazards model

\begin{tabular}{|c|c|c|c|c|c|c|}
\hline \multirow[t]{3}{*}{ Covariate } & \multicolumn{6}{|l|}{ Species } \\
\hline & \multicolumn{3}{|c|}{ C. pamphilus $(n=853)$} & \multicolumn{3}{|c|}{ M. jurtina $(n=420)$} \\
\hline & Coef & $P$ & 1:i:h & Coef & $P$ & l:i:h \\
\hline Gender (male) & -0.241 & 0.014 & & -0.101 & 0.53 & \\
\hline Year (2007) & -0.018 & 0.87 & & -0.896 & 0.005 & \\
\hline Low:intermediate temperature & 0.032 & 0.74 & $a: a: b$ & -0.328 & 0.28 & $a: a: b$ \\
\hline Low:high temperature & -0.487 & 0.01 & & -0.795 & 0.013 & \\
\hline Intermediate:high temperature & -0.519 & 0.002 & & -0.467 & 0.008 & \\
\hline Low:intermediate radiation & 0.09 & 0.39 & $a: a: b$ & -0.031 & 0.83 & $\mathrm{a}: \mathrm{a}: \mathrm{a}$ \\
\hline Low:high radiation & 0.321 & 0.01 & & -0.076 & 0.67 & \\
\hline Intermediate:high radiation & 0.231 & 0.046 & & -0.045 & 0.79 & \\
\hline Low:intermediate cloudiness & 0.147 & 0.15 & $a: a b: b$ & -0.376 & 0.05 & $\mathrm{a}: \mathrm{a}: \mathrm{a}$ \\
\hline Low:high cloudiness & 0.285 & 0.017 & & -0.296 & 0.12 & \\
\hline Intermediate:high cloudiness & 0.138 & 0.152 & & 0.080 & 0.58 & \\
\hline Low:intermediate wind speed & 0.277 & 0.006 & $a: b: b$ & -0.092 & 0.46 & $\mathrm{a}: \mathrm{a}: \mathrm{a}$ \\
\hline Low:high wind speed & 0.414 & 0.0004 & & 0.483 & 0.17 & \\
\hline Intermediate:high wind speed & 0.137 & 0.17 & & 0.575 & 0.10 & \\
\hline \multirow[t]{3}{*}{ Covariate } & \multicolumn{6}{|l|}{ Species } \\
\hline & \multicolumn{3}{|c|}{ M. athalia $(n=174)$} & \multicolumn{3}{|c|}{$P . \operatorname{argus}(n=141)$} \\
\hline & Coef & $P$ & 1:i:h & Coef & $P$ & l:i:h \\
\hline Gender (male) & -0.011 & 0.96 & & -0.599 & 0.12 & \\
\hline Year (2007) & -1.008 & 0.025 & & 0.334 & 0.14 & \\
\hline Low:intermediate temperature & -0.99 & 0.19 & $a b: a: b$ & & & \\
\hline Low:high temperature & 0.467 & 0.66 & & & & \\
\hline Intermediate:high temperature & 1.456 & 0.0495 & & & & \\
\hline Low:intermediate radiation & 1.129 & 0.12 & $a b: a: b$ & -0.574 & 0.011 & $a: b: b$ \\
\hline Low:high radiation & -0.2 & 0.82 & & -0.795 & 0.002 & \\
\hline Intermediate:high radiation & -1.329 & 0.008 & & -0.221 & 0.36 & \\
\hline Low:intermediate cloudiness & 2.893 & 0.002 & $a: b: b$ & & & \\
\hline Low:high cloudiness & 3.791 & 0.001 & & & & \\
\hline Intermediate:high cloudiness & 0.898 & 0.17 & & & & \\
\hline Low:intermediate wind speed & -0.145 & 0.58 & $\mathrm{a}: \mathrm{a}: \mathrm{a}$ & & & \\
\hline Low:high wind speed & NA & NA & & & & \\
\hline Intermediate:high wind speed & 0.145 & 0.58 & & & & \\
\hline
\end{tabular}

$n$ is number of bouts; 1:i:h is category abbreviations: low:intermediate:high; NA could not be tested due to lack of data; effects are on tendencies to stop flying; $P$ values based on $Z$ score; categories sharing the same letter $(\mathrm{a}, \mathrm{b}, \mathrm{c})$ are not significantly different $(P>0.05)$

$P<0.0001$ resp.) and $M$. athalia $(P=0.038$ for intermediate cloudiness only), while it was enhanced at intermediate cloudiness for M. jurtina $(P=0.015)$. The tendency to start flying was not affected by wind speed, while in general it was enhanced for males (C. pamphilus, $P=0.026 ; P$. argus, $P=0.045$ ). 
Table 4 Results survival analysis for non-flight behaviour based on multivariate Cox's proportional hazards model

\begin{tabular}{|c|c|c|c|c|c|c|}
\hline \multirow[t]{3}{*}{ Covariate } & \multicolumn{6}{|l|}{ Species } \\
\hline & \multicolumn{3}{|c|}{ C. pamphilus $(n=870)$} & \multicolumn{3}{|c|}{ M. jurtina $(n=406)$} \\
\hline & Coef & $P$ & 1:i:h & Coef & $P$ & l:i:h \\
\hline Gender (male) & 0.324 & 0.0003 & & 0.039 & 0.82 & \\
\hline Year (2007) & 0.169 & 0.082 & & 0.6124 & 0.078 & \\
\hline Low:intermediate temperature & -0.112 & 0.2 & a:a:na & 0.779 & 0.018 & $a: b: b$ \\
\hline Low:high temperature & NA & NA & & 0.716 & 0.039 & \\
\hline Intermediate:high temperature & NA & NA & & -0.063 & 0.72 & \\
\hline Low:intermediate radiation & 0.282 & 0.004 & $a: b: b$ & -0.004 & 0.98 & $\mathrm{a}: \mathrm{a}: \mathrm{a}$ \\
\hline Low:high radiation & 0.32 & 0.004 & & -0.222 & 0.21 & \\
\hline Intermediate:high radiation & 0.038 & 0.68 & & -0.218 & 0.18 & \\
\hline Low:intermediate cloudiness & -0.23 & 0.026 & $a: b: c$ & 0.457 & 0.015 & $a c: b: c$ \\
\hline Low:high cloudiness & -0.651 & 0.0000 & & 0.109 & 0.55 & \\
\hline Intermediate:high cloudiness & -0.422 & 0.002 & & -0.348 & 0.017 & \\
\hline Low:intermediate wind speed & -0.071 & 0.41 & a:a:na & -0.113 & 0.39 & $\mathrm{a}: \mathrm{a}: \mathrm{a}$ \\
\hline Low:high wind speed & NA & NA & & -0.343 & 0.36 & \\
\hline Intermediate:high wind speed & NA & NA & & -0.230 & 0.52 & \\
\hline \multirow[t]{3}{*}{ Covariate } & \multicolumn{6}{|l|}{ Species } \\
\hline & \multicolumn{3}{|c|}{ M. athalia $(n=182)$} & \multicolumn{3}{|c|}{$P . \operatorname{argus}(n=146)$} \\
\hline & Coef & $P$ & l:i:h & Coef & $P$ & l:i:h \\
\hline Gender (male) & -0.086 & 0.65 & & 0.695 & 0.045 & \\
\hline Year (2007) & 1.004 & 0.028 & & -0.72 & 0.002 & \\
\hline Low:intermediate temperature & 0.248 & 0.68 & $a b: a: b$ & & & \\
\hline Low:high temperature & -1.053 & 0.22 & & & & \\
\hline Intermediate:high temperature & -1.301 & 0.038 & & & & \\
\hline Low:intermediate radiation & 1.467 & 0.004 & $a: b: b$ & 0.217 & 0.33 & $a b: a: b$ \\
\hline Low:high radiation & 2.14 & 0.002 & & -0.373 & 0.12 & \\
\hline Intermediate:high radiation & 0.673 & 0.109 & & -0.591 & 0.01 & \\
\hline Low:intermediate cloudiness & -1.463 & 0.038 & $\mathrm{a}: \mathrm{b}: \mathrm{a}$ & & & \\
\hline Low:high cloudiness & -0.065 & 0.94 & & & & \\
\hline Intermediate:high cloudiness & 1.399 & 0.049 & & & & \\
\hline Low:intermediate wind speed & -0.196 & 0.49 & a:a:a & & & \\
\hline Low:high wind speed & NA & NA & & & & \\
\hline Intermediate:high wind speed & -0.196 & 0.49 & & & & \\
\hline
\end{tabular}

$n$ is number of bouts; 1:i:h is category abbreviations: low:intermediate:high; NA could not be tested due to lack of data; effects are on tendencies to start flying; $P$ values based on $Z$ score; categories sharing the same letter $(\mathrm{a}, \mathrm{b}, \mathrm{c})$ are not significantly different $(P>0.05)$

The influence of measured wind speed on observed duration of flying and non-flying bouts for $C$. pamphilus is summarized in the scheme in Appendix Fig. 5, based on both Tables 3 and 4 . The width of the bars shows the duration of flying and non-flying bouts relative to the baseline situation (wind speed $\leq 1 \mathrm{Bft}$ ). 
Time budget analysis

The proportion of time spent flying was not affected by temperature (Fig. 2). This proportion was less for low radiation, compared with intermediate and high radiation (C. pamphilus, $W_{\text {low:intermediate }}=715.5, P=0.029 ; W_{\text {low:high }}=161.5, P=0.042$ ). The proportion of time spent flying was affected by cloudiness in various ways, depending on the species. It decreased from low to intermediate to high cloudiness for $C$. pamphilus $\left(W_{\text {low:intermediate }}=584, P=0.029 ; W_{\text {low:high }}=513, P=0.001 ; W_{\text {intermediate: }}\right.$ high $=1124$, $P=0.019$ ), it showed an optimum at intermediate cloudiness for $M$. jurtina (less time was devoted to flight behaviour under low and high cloudiness in respect to intermediate cloudiness; $W_{\text {low:intermediate }}=10, P=0.009 ; W_{\text {intermediate:high }}=208, P=0.026$ ), and it showed a minimum for intermediate cloudiness for $M$. athalia (more time was devoted to flight behaviour under low and high cloudiness in respect to intermediate cloudiness;

$W_{\text {low:intermediate }}=53, P=0.028 ; W_{\text {intermediate:high }}=8, P=0.043$ ). The proportion of time spent flying was less at low wind speed than at intermediate and high wind speed (C. pamphilus, $W_{\text {low:intermediate }}=705, P=0.036 ; W_{\text {low:high }}=444, P=0.014$ ).

Spatial analysis

The tortuosity of pathways of non of the species was affected by the weather variables (Table 5). Net displacements were greater at higher temperatures (C. pamphilus, $P=0.003 ; M$. athalia, $P=0.034)$. However, $M$. jurtina showed increased net displacements at lower temperatures $(P=0.001)$ and at higher radiation $(P=0.004)$ and $M$. athalia showed greater displacements at higher wind speed $(P=0.0283)$.

Pathway tortuosity of $M$. jurtina in non-habitat was smaller than within its habitat (Fig. 3; $W=319, P=0.002$ ). Net displacements of pathways of $M$. jurtina were greater in non-habitat $(W=33, P<0.0001)$.

\section{Colonization frequency}

For $C$. pamphilus, colonization frequencies decreased with average cloudiness, experienced during the flight periods of the previous year, and with average wind speed during the flight periods of the current year (Table 6; best model). Cloudiness showed as well negative effects on flight propensity and proportion, and wind speed showed a negative effect on net displacement in the field study. For M. jurtina, colonization frequencies increased with average radiation during the flight period of the current year. Radiation showed as well a positive effect on net displacement in the field study. Models incorporating average temperature, maximum temperature, or cloudiness performed also well, due to high correlations between weather variables. For $P$. argus, colonization frequencies increased with average temperature during the flight period of the current year and average wind speed during the flight period of the previous year. In the field study, neither weather variables significantly affected the flight behaviour of $P$. argus.

\section{Discussion}

We have shown that duration of flying bouts and net displacement of butterflies generally increased with temperature; duration of flying bouts and proportion of time spent flying decreased with cloudiness. When butterflies fly longer bouts, start flying more readily, 
(a)

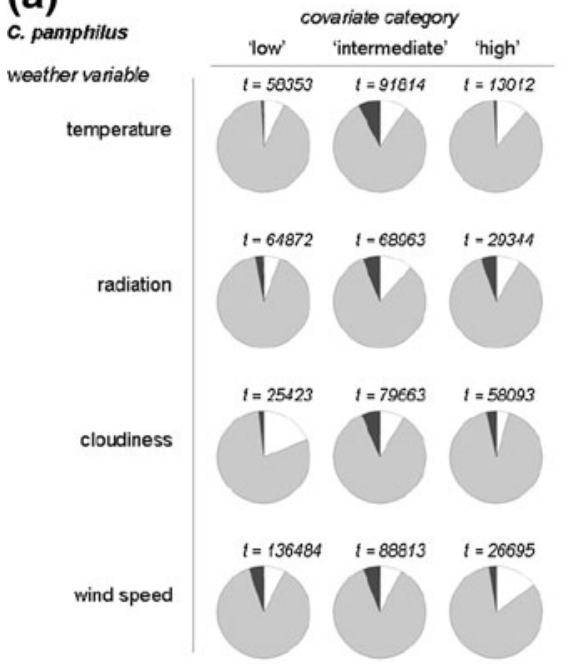

(c)

M. athalia

weather variable

temperature
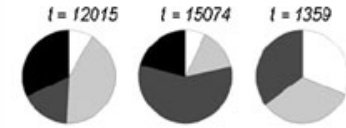

cloudiness
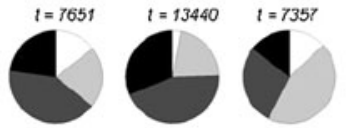

wind speed

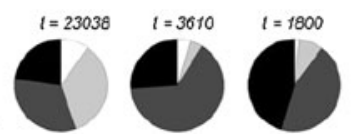

(b)

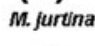

weather variable

temperature
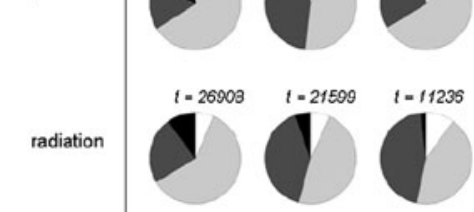

cloudiness

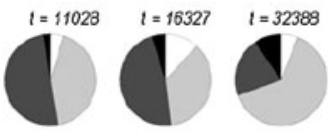

wind speed

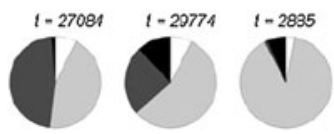

(d)

woather variable

temperature

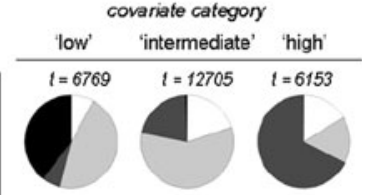

radiation

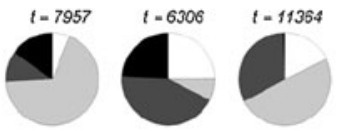

cloudiness
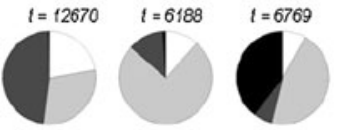

wind speed
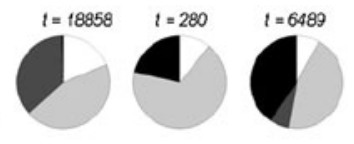

flying:

$\square$ resting;

nectaring;

basking; $\mathrm{t}=$ recorded time (s)

Fig. 2 Proportion of time devoted to certain behaviour is shown per weather variable and covariate category. White slices represent flight behaviour; darker tones indicate non-flight behaviour; $t=$ recorded time per covariate category in seconds

spend more time flying, and fly over longer distances, we expect dispersal propensity to increase. Furthermore, the higher the flight activity, the higher the probability to leave a patch. We have shown that colonization frequencies increased with temperature and radiation and decreased with cloudiness. We conclude that these results suggest that patches of habitat in a fragmented landscape are more readily colonized in periods with weather conditions favourable for dispersal. Therefore, we argue that climate change not only aggravates the impacts of habitat fragmentation on populations (Opdam and Wascher 
Table 5 Effects of weather variables on tortuosity and net displacements of pathways for best models, based on AIC

\begin{tabular}{|c|c|c|c|c|}
\hline & \multicolumn{4}{|l|}{ Species } \\
\hline & C. pamphilus & M. jurtina & M. athalia & P. argus \\
\hline \multicolumn{5}{|l|}{ Tortuosity } \\
\hline \multicolumn{5}{|l|}{ Best model } \\
\hline \multicolumn{5}{|l|}{ AIC } \\
\hline Temperature & -182.88 & -99.75 & -10.30 & -24.73 \\
\hline Temperature + radiation & -181.15 & -97.90 & -12.47 & -23.07 \\
\hline Radiation & -181.80 & -99.36 & -10.07 & -24.97 \\
\hline Full model & -179.37 & -95.96 & -9.94 & -19.60 \\
\hline Null model & -182.55 & -101.28 & -11.58 & -26.66 \\
\hline \multicolumn{5}{|l|}{ Estimates best models } \\
\hline Intercept & 0.300 & 0.255 & 0.916 & 0.214 \\
\hline Temperature & -0.004 & -0.001 & -0.033 & - \\
\hline Radiation & - & - & -0.010 & 0.001 \\
\hline Cloudiness & - & - & - & - \\
\hline Wind speed & - & - & - & - \\
\hline \multicolumn{5}{|l|}{ Net displacement } \\
\hline \multicolumn{5}{|l|}{ Best model } \\
\hline \multicolumn{5}{|l|}{ AIC } \\
\hline Temperature & 731.82 & 436.00 & 120.93 & \\
\hline Temperature + radiation & 733.72 & 428.97 & 122.79 & \\
\hline Temperature + radiation + wind speed & 733.46 & 430.50 & 116.72 & \\
\hline Radiation & 738.74 & 438.82 & 123.06 & $81.42^{\mathrm{a}}$ \\
\hline Full model & 733.53 & 432.48 & 117.04 & \\
\hline Null model & 739.12 & 441.93 & 124.03 & 81.38 \\
\hline \multicolumn{5}{|l|}{ Estimates best models } \\
\hline Intercept & -44.988 & 40.544 & -338.712 & 17.519 \\
\hline Temperature & 3.902 & -1.619 & 14.806 & - \\
\hline Radiation & - & 1.2961 & -3.935 & 0.784 \\
\hline Cloudiness & - & - & - & - \\
\hline Wind speed & - & - & 76.085 & - \\
\hline
\end{tabular}

Bold value represents best model per species

"-" not included in best model

a Only radiation used in analysis

2004; Travis 2003; Warren et al. 2001), but also may diminish these impacts by enhancing dispersal and colonization. This is indeed shown in the successful northwards range expansion of mobile generalist species (Warren et al. 2001). Further evidence supporting this view was found by Møller et al. (2006), who found increased dispersal tendencies in a coastal seabird, the Arctic tern, in relation with long-term climate change. Moreover, increased dispersal tendencies in bush crickets in response to improving environmental conditions at their range margins have been reported by Thomas et al. (2001) and Simmons and Thomas (2004). Our study shows that increased dispersal under climate change may also apply to moderately mobile species. 

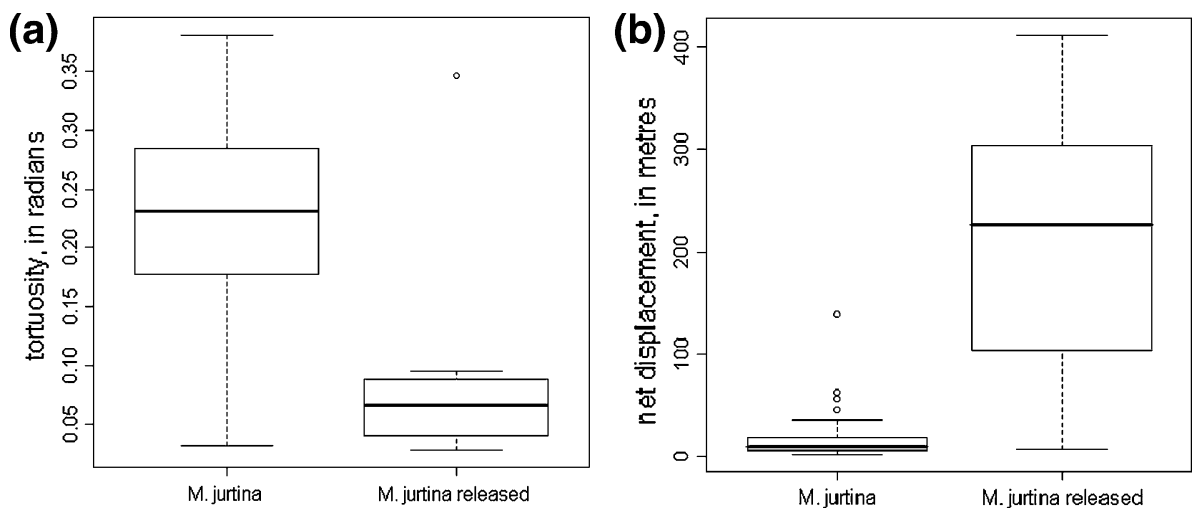

Fig. 3 Differences in tortuosity $(\mathrm{A} ; W=319, P=0.002)$ and net displacements $(\mathrm{B} ; W=33$, $P=3.552 \mathrm{E}-05)$ of pathways of released and non-released individuals of $M$. jurtina

Table 6 Effects of average weather variables on colonization frequencies, measured over flight periods during 1991-2008; for best models, based on AIC

\begin{tabular}{lll} 
Species & \\
\hline C. pamphilus & M. jurtina & P. argus \\
\hline
\end{tabular}

Best model

AIC

Cloudiness $t-1+$ wind speed $t$

Radiation $t$

Temperature $t+$ wind speed $t-1$

Full model

Null model

Estimates best models

Intercept

Temperature $t$

Radiation $t$

Cloudiness $t-1$

Wind speed $\mathrm{t}$

Wind speed $t-1$
68.50

81.35

74.42

66.25

79.47

29.408

$-$

$-$

$-2.950$

$-0.377$

$-$
60.05

54.19

56.09

62.11

57.04

95.52

89.91

83.25

92.66

93.99

$-35.527$

0.003

$-$

$-$

$-$
$-$

$-$

0.642

Bold value represents best model per species

“_" not included in best model

a Colonization frequencies correlated to population indices and weather conditions experienced during the flight period of the same year $(t)$ or the previous year $(t-1)$

b Weather conditions during flight periods first and second generation of $C$. pamphilus taken together

The tendency to start flying was enhanced by increasing radiation (C. pamphilus, M. athalia), as expected. Males of $C$. pamphilus exhibited longer flights and flew off more readily than females. This was also found by Wickman (1985), and can be related to matelocating and territorial behaviour (cf. Fischer and Fiedler 2001 for Lycaena hippothoe; and Merckx et al. 2006; Shreeve 1984; Van Dyck and Matthysen 1998 for Pararge aegeria).

The proportion of time spent flying was less at low solar radiation for C. pamphilus. For the other species this effect also seemed apparent (see Fig. 2), but effects were not 
significant. This may be due to two reasons: first, for the time budget analyses (in contrast to the survival analyses), only the effects of single weather variables were tested, without correction for other weather variables that acted simultaneously. Therefore, the effect of radiation can be masked by effects of other weather parameters. Second, in the field, each individual was tracked only once, under a particular set of weather conditions. Between individuals, the proportion of time spent flying differed greatly (see Appendix Table 9), so that differences in flight behaviour as a function of weather could not be demonstrated. The results of the survival analyses may also have been affected by differences between individuals. Unfortunately, tracking individuals more than once and under different weather conditions, was not practically feasible, because the weather did not change drastically within an individual's lifespan.

We expected an increase in cloudiness to shorten flying bouts, reduce the tendency to start flying, and decrease the proportion of time spent flying (after Dennis and Sparks 2006). We can recognize these effects in the behaviour of C. pamphilus (Tables 3, 4; Fig. 2a). For M. jurtina, however, the proportion of time spent flying showed an optimum at intermediate cloudiness (between 15 and 70\%; Fig. 2b). Also, the tendency to start flying was enhanced by intermediate cloudiness (Table 4). We observed the opposite response for M. athalia (Fig. 2c). This result is difficult to explain and may be due to the small number of observations for $M$. athalia.

The weather variables did not show any effects on tortuosity. Net displacement, however, increased with higher temperature ( $C$. pamphilus and $M$. athalia), radiation (M. jurtina), and wind speed ( $M$. athalia). Individuals flying with increased net displacement but without altering tortuosity, will explore larger parts of their environment. In doing so, explorative individuals may increase the probability to encounter suitable habitat.

Released individuals of $M$. jurtina showed flight patterns resembling those found by Conradt et al. (2000): the butterflies either followed a more or less linear route or flew in large petal-like loops around the release site. Both types of flight pattern are significantly less tortuous than the patterns shown by individuals of $M$. jurtina flying within their habitat. Moreover, all but one of the individuals crossed longer distances outside their habitat than within. These findings confirm the statement by Van Dyck and Baguette (2005) that movement behaviour of animals outside their habitat differs considerably in speed and tortuosity from the routine explorative movements for local resource-use purposes. Flying straight over large distances in non-habitat is an efficient way to find new suitable habitat (Zollner and Lima 1999). Individuals of M. jurtina indeed explore the landscape efficiently, which is shown by the rapid colonization of the Dutch polder Flevoland after reclamation (Bos et al. 2006), over distances of $20 \mathrm{~km}$ within two decades after the first sightings.

We propose that climate change may diminish the effects of fragmentation by enhancing flight behaviour and dispersal of butterflies, and presumably also other ectothermic species. However, the probability to encounter suitable conditions for flight activity during dispersal might prevent this higher activity to lead to higher dispersal. If this probability is low, dispersal is expected to be less successful as dispersing individuals will take longer to reach a next patch of suitable habitat. These individuals will therefore have to remain longer in a hostile environment with reduced chances of survival. We propose that adding more suitable habitat should thus lead to more efficient and more successful dispersal at an increased survival rate. In butterflies, adopting straight movements for dispersal reduces its costs in fragmented landscapes (Schtickzelle et al. 2007). Butterflies might therefore prefer continuous, line-shaped connections or corridors (cf. Noordijk et al. 2008).

A colonization event for a particular species was defined as a sighting of at least one individual after 2 years of absence. The observation of a single individual can be 
Table 7 Response on climate change regarding flight behaviour and mobility

\begin{tabular}{lllll}
\hline Type of flight behaviour/mobility per species & C. pamphilus & M. jurtina & M. athalia & P. argus \\
\hline Duration of flying bouts & + & + & + & + \\
Tendency to start flying & + & + & + & $=$ \\
Proportion of time spent flying & + & - & + & $=$ \\
Tortuosity & $=$ & $=$ & $=$ & $=$ \\
Net displacement & + & - & + & $=$ \\
\hline
\end{tabular}

+ , increase; - , decrease; $=$, neutral

considered as a conservative estimate of a colonization event. The transect data are taken from optimal habitat and necessarily constitute samples from a population. Therefore, it is quite likely that the observation of only a single individual on a given transect in a particular year is rather representing a low population density of the sampled population rather than a vagrant individual. In any case, our results are not affected by applying a threshold of more than 1 individual. The majority (62\%) of the identified colonizations concerned multiple individuals and the correlation between the total number of colonizations in different years with and without the threshold was very high $(r=0.93)$.

\section{Implications of future climate}

Due to climate change, weather conditions in the Netherlands are predicted to change significantly during summer (Van den Hurk et al. 2007). Depending on the climate scenario, average annual temperature rise is predicted $1-2^{\circ} \mathrm{C}$ until 2050 . More hot (and dry) periods are predicted to occur as a result of more frequent easterly winds. Our results suggest that especially habitat generalists such as C. pamphilus and M. jurtina will respond by flying in longer bouts (Table 7). Net displacement of the habitat specialist M. athalia is expected to increase with more frequent easterly winds bringing clearer skies and higher solar radiation. Especially $C$. pamphilus and $M$. athalia may then be expected to fly more readily and over longer periods, which might enhance dispersal.

The possibility to reach new habitats is a prerequisite under changing climatic conditions (Vos et al. 2008). Individuals must be able to cross distances over unsuitable environments. This study indicates that climate change may increase dispersal propensity in butterflies, as ectothermic species with generally poor mobility. Incorporation of these insights in metapopulation models is necessary to improve predictions on the effects of climate change on shifting ranges.

Acknowledgments This research was funded by the Dutch national research programme 'Climate Changes Spatial Planning' and is part of the strategic research programme 'Sustainable spatial development of ecosystems, landscapes, seas and regions' (Project Ecological Resilience) which is funded by the Dutch Ministry of Agriculture, Nature Conservation and Food Quality, and carried out by Wageningen University and Research Centre. The Dutch Butterfly Monitoring Scheme is a joint project by Dutch Butterfly Conservation and Statistics Netherlands (CBS), supported financially by the Dutch Ministry of Agriculture, Nature and Food Quality. We thank Paul Opdam for helpful comments on the manuscript; the staff of the National Park "De Hoge Veluwe" for permission to work in the Park; Larissa Conradt, René Jochem, Ruut Wegman, and members of the "Friends of the Hoge Veluwe" Fauna working group for practical help and tips on the fieldwork; and Gerrit Gort and Hans Baveco for help on statistics.

Open Access This article is distributed under the terms of the Creative Commons Attribution Noncommercial License which permits any noncommercial use, distribution, and reproduction in any medium, provided the original author(s) and source are credited. 


\section{Appendix 1}

See Fig. 4.

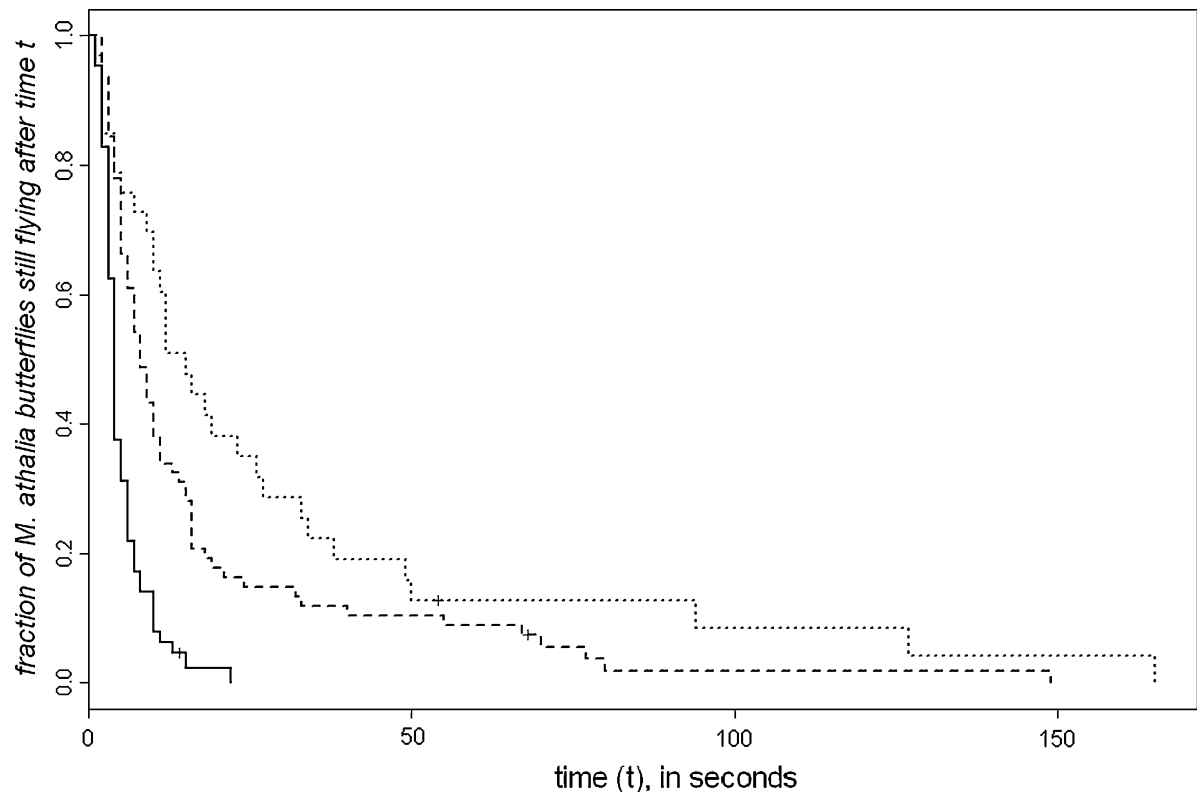

Fig. 4 Kaplan-Meier survival curve for flying bouts of $M$. athalia with temperature as single covariate. Under low temperature (solid line; less or equal to $14^{\circ} \mathrm{C}$ ), butterflies terminate flying bouts sooner than under intermediate temperature (between 14 and $25^{\circ} \mathrm{C}$; dashed line; $P=2.9 \mathrm{E}-08$ ) and high temperature (more than $25^{\circ} \mathrm{C}$; dotted line; $P=1.1 \mathrm{E}-09$ ).

\section{Appendix 2}

See Table 8.

Table 8 Correlations between covariates from field study

\begin{tabular}{|c|c|c|c|c|c|c|}
\hline & \multicolumn{6}{|c|}{ Species } \\
\hline & \multicolumn{6}{|c|}{ C. pamphilus } \\
\hline & $G$ & $Y$ & $T$ & $R$ & $C$ & $W$ \\
\hline Gender $(G)$ & 1 & & & & & \\
\hline Year $(Y)$ & 0.30 & 1 & & & & \\
\hline Temperature $(T)$ & 0.03 & -0.42 & 1 & & & \\
\hline Radiation $(R)$ & -0.05 & -0.23 & 0.44 & 1 & & \\
\hline Cloudiness $(C)$ & -0.09 & 0.31 & -0.67 & -0.30 & 1 & \\
\hline Wind speed $(W)$ & -0.06 & -0.07 & 0.05 & 0.33 & -0.13 & 1 \\
\hline
\end{tabular}


Table 8 continued

\begin{tabular}{|c|c|c|c|c|c|c|}
\hline & \multicolumn{6}{|c|}{ Species } \\
\hline & \multicolumn{6}{|c|}{ M. jurtina } \\
\hline & $G$ & $Y$ & $T$ & $R$ & $C$ & $W$ \\
\hline Gender $(G)$ & 1 & & & & & \\
\hline Year $(Y)$ & 0.33 & 1 & & & & \\
\hline Temperature $(T)$ & -0.21 & -0.84 & 1 & & & \\
\hline Radiation $(R)$ & 0.15 & 0.20 & -0.08 & 1 & & \\
\hline Cloudiness $(C)$ & 0.20 & -0.20 & 0.09 & -0.31 & 1 & \\
\hline \multirow[t]{4}{*}{ Wind speed $(W)$} & 0.19 & 0.01 & 0.09 & 0.16 & 0.37 & 1 \\
\hline & \multicolumn{6}{|c|}{ Species } \\
\hline & \multicolumn{6}{|c|}{ M. athalia } \\
\hline & $G$ & $Y$ & $T$ & $R$ & $C$ & $W$ \\
\hline Gender $(G)$ & 1 & & & & & \\
\hline Year $(Y)$ & 0.38 & 1 & & & & \\
\hline Temperature $(T)$ & -0.35 & -0.92 & 1 & & & \\
\hline Radiation $(R)$ & -0.08 & -0.16 & 0.18 & 1 & & \\
\hline Cloudiness $(C)$ & 0.10 & 0.67 & -0.79 & -0.30 & 1 & \\
\hline \multirow[t]{4}{*}{ Wind speed $(W)$} & -0.07 & 0.11 & -0.09 & 0.44 & 0.06 & 1 \\
\hline & \multicolumn{6}{|c|}{ Species } \\
\hline & \multicolumn{6}{|c|}{ P. argus } \\
\hline & $G$ & $Y$ & $T$ & $R$ & $C$ & $W$ \\
\hline Year $(Y)$ & 0.18 & 1 & & & & \\
\hline Temperature $(T)$ & 0.01 & -0.84 & 1 & & & \\
\hline Radiation $(R)$ & 0.00 & -0.32 & 0.06 & 1 & & \\
\hline Cloudiness $(C)$ & 0.07 & 0.87 & -0.65 & -0.55 & 1 & \\
\hline Wind speed $(W)$ & 0.18 & 0.99 & -0.83 & -0.30 & 0.86 & 1 \\
\hline
\end{tabular}

\section{Appendix 3}

See Fig. 5.

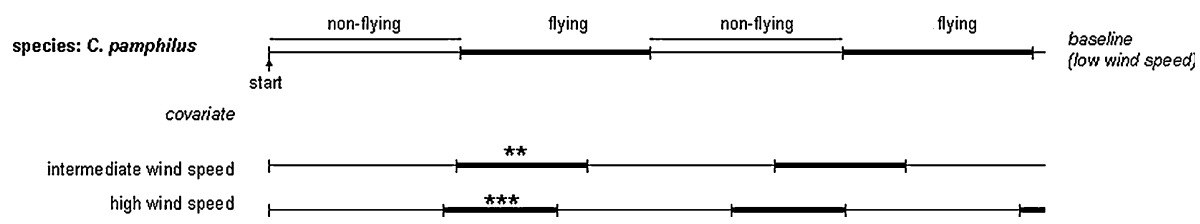

Fig. 5 Effect of wind speed on observed duration of flying and non-flying bouts for C. pamphilus, based on survival analysis. Width of bars shows duration of behaviour type relative to baseline situation (low wind speed), where non-flight behaviour can consist of more than one behaviour type; $P$ values from $\mathrm{Z}$ score test: $* * P<0.01$; $* * * P<0.005$; number of flying bouts: 853 ; number of non-flying bouts: 870 . 


\section{Appendix 4}

See Table 9.

Table 9 Number of individuals, and mean and standard deviation in proportion of time spent flying per individual

\begin{tabular}{|c|c|c|c|c|c|c|c|}
\hline Species & Statistic & Low, $T$ & Intermediate, $T$ & High, $T$ & Low, $R$ & Intermediate, $R$ & High, $R$ \\
\hline \multirow[t]{3}{*}{ C. pamphilus } & $n$ & 37 & 57 & 8 & 40 & 49 & 13 \\
\hline & Mean & 11.09 & 13.35 & 14.94 & 7.77 & 15.97 & 15.21 \\
\hline & Stdev & 16.20 & 18.45 & 23.96 & 12.35 & 20.85 & 18.93 \\
\hline \multirow[t]{3}{*}{ M. jurtina } & $n$ & 15 & 21 & 5 & 18 & 15 & 8 \\
\hline & Mean & 15.70 & 22.05 & 11.00 & 19.16 & 8.37 & 26.17 \\
\hline & Stdev & 24.18 & 25.09 & 11.58 & 24.95 & 9.25 & 25.50 \\
\hline \multirow[t]{3}{*}{ M. athalia } & $n$ & 6 & 9 & 7 & 9 & 11 & 2 \\
\hline & Mean & 3.07 & 19.13 & 22.81 & 10.80 & 14.83 & 44.99 \\
\hline & Stdev & 2.63 & 23.77 & 23.30 & 12.20 & 23.35 & 25.41 \\
\hline \multirow[t]{3}{*}{ P. argus } & $n$ & 6 & 10 & 6 & 8 & 5 & 9 \\
\hline & Mean & 9.87 & 20.84 & 24.05 & 11.30 & 25.03 & 21.81 \\
\hline & Stdev & 6.98 & 23.76 & 25.58 & 10.49 & 22.52 & 26.83 \\
\hline Species & Statistic & Low, $C$ & Intermediate, $C$ & High, $C$ & Low, $W$ & Intermediate, $W$ & High, $W$ \\
\hline \multirow[t]{3}{*}{ C. pamphilus } & $n$ & 18 & 48 & 36 & 21 & 51 & 30 \\
\hline & Mean & 26.84 & 12.24 & 6.12 & 22.95 & 10.36 & 9.35 \\
\hline & Stdev & 29.26 & 14.86 & 8.62 & 26.54 & 13.28 & 15.50 \\
\hline \multirow[t]{3}{*}{ M. jurtina } & $n$ & 6 & 13 & 22 & 19 & 20 & 2 \\
\hline & Mean & 4.52 & 31.54 & 14.38 & 17.05 & 21.14 & 3.44 \\
\hline & Stdev & 3.37 & 25.81 & 22.01 & 25.87 & 22.12 & 2.99 \\
\hline \multirow[t]{3}{*}{ M. athalia } & $n$ & 8 & 8 & 6 & 19 & 2 & 1 \\
\hline & Mean & 29.29 & 2.90 & 15.46 & 17.92 & 4.03 & 1.83 \\
\hline & Stdev & 28.30 & 2.43 & 12.57 & 21.94 & 1.37 & - \\
\hline \multirow[t]{3}{*}{$P$. argus } & $n$ & 11 & 5 & 6 & 16 & 1 & 5 \\
\hline & Mean & 23.63 & 18.54 & 9.87 & 22.04 & 10.71 & 9.71 \\
\hline & Stdev & 25.89 & 20.01 & 6.98 & 23.65 & - & 7.79 \\
\hline
\end{tabular}

\section{References}

Anderson BJ, Akcakaya HR, Araujo MB, Fordham DA, Martinez-Meyer E, Thuiller W, Brook BW (2009) Dynamics of range margins for metapopulations under climate change. Proc R Soc B Biol Sci 276:1415-1420

Barry RG, Chorley RJ (2003) Atmosphere, weather and climate. Routledge, London

Berry PM, Jones AP, Nicholls RJ, Vos CC (2007) Assessment of the vulnerability of terrestrial and coastal habitats and species in Europe to climate change, Annex 2 of planning for biodiversity in a changing climate-BRANCH project. Final report, Natural England

Bos F, Bosveld M, Groenendijk D, Van Swaay C, Wynhoff I (2006) De dagvlinders van Nederland, verspreiding en bescherming (Lepidoptera: Hesperioidea, Papilionoidea)_Nederlandse Fauna 7. KNNV Uitgeverij and European Invertebrate Survey-Nederland, Leiden, the Netherlands, Nationaal Natuurhistorisch Museum Naturalis 
Brattstrom O, Kjellen N, Alerstam T, Akesson S (2008) Effects of wind and weather on red admiral, Vanessa atalanta, migration at a coastal site in southern Sweden. Anim Behav 76:335-344

Brown ES (1970) Nocturnal insect flight direction in relation to wind. Proc R Entomol Soc Lond A Gen Entomol 45:39-43

Burnham KP, Anderson DR (2002) Model selection and multimodel inference: a practical informationtheoretic approach. Springer, Verlag

Clench HK (1966) Behavioral thermoregulation in butterflies. Ecology 47:1021-1034

Conradt L, Bodsworth EJ, Roper TJ, Thomas CD (2000) Non-random dispersal in the butterfly Maniola jurtina: implications for metapopulation models. Proc R Soc Lond B Biol Sci 267:1505-1510

Conradt L, Roper TJ, Thomas CD (2001) Dispersal behaviour of individuals in metapopulations of two British butterflies. Oikos 95:416-424

Dennis RLH, Sparks TH (2006) When is a habitat not a habitat? Dramatic resource use changes under differing weather conditions for the butterfly Plebejus argus. Biol Conserv 129:291-301

Devictor V, Julliard R, Couvet D, Jiguet F (2008) Birds are tracking climate warming, but not fast enough. Proc R Soc B Biol Sci 275:2743-2748

Douwes P (1976) Activity in Heodes virgaureae (Lep Lycaenidae) in relation to air temperature, solarradiation, and time of day. Oecologia 22:287-298

Fischer K, Fiedler K (2001) Resource-based territoriality in the butterfly Lycaena hippothoe and environmentally induced behavioural shifts. Anim Behav 61:723-732

Haccou P, Hemerik L (1985) The influence of larval dispersal in the cinnabar moth (Tyria jacobaeae) on predation by the red wood ant (Formica polyctena) — an analysis based on the proportional hazards model. J Anim Ecol 54:755-769

Haccou P, Meelis E (1992) Statistical analysis of behavioural data. An approach based on time-structured models. Oxford University Press, Oxford

Hill JK, Thomas CD, Fox R, Telfer MG, Willis SG, Asher J, Huntley B (2002) Responses of butterflies to twentieth century climate warming: implications for future ranges. Proc R Soc Lond B Biol Sci 269:2163-2171

Ihaka R, Gentleman R (1996) R package, 2.9.0 edn. http://cran.r-project.org

Jochem R (2006) GPS2Shape, Wageningen

Kalbfleisch JD, Prentice RL (2002) The statistical analysis of failure time data. Wiley Series in Probability and Statistics, New York

Kleinbaum DG, Klein M (2005) Survival analysis: a self-learning text. Springer, New York

Merckx T, Karlsson B, Van Dyck H (2006) Sex- and landscape-related differences in flight ability under suboptimal temperatures in a woodland butterfly. Funct Ecol 20:436-441

Miron G, Desrosiers G, Retiere C, Masson S (1992) Variations in time budget of the polychaete Nereis virens as a function of density and acclimation after introduction to a new burrow. Mar Biol 114:41-48

Mitikka V, Heikkinen RK, Luoto M, Araujo MB, Saarinen K, Poyry J, Fronzek S (2008) Predicting range expansion of the map butterfly in Northern Europe using bioclimatic models. Biodivers Conserv 17:623-641

Møller AP, Flensted-Jensen E, Mardal W (2006) Dispersal and climate change: a case study of the Arctic tern Sterna paradisaea. Glob Change Biol 12:2005-2013

Morales JM, Ellner SP (2002) Scaling up animal movements in heterogeneous landscapes: The importance of behavior. Ecology 83:2240-2247

Nathan R, Getz WM, Revilla E, Holyoak M, Kadmon R, Saltz D, Smouse PE (2008) A movement ecology paradigm for unifying organismal movement research. Proc Natl Acad Sci USA 105:19052-19059

Noordijk J, Sýkora KV, Schaffers AP (2008) The conservation value of sandy highway verges for arthropods-implications for management. Proc Neth Entomol Soc Meet 19:75-93

Opdam P, Wascher D (2004) Climate change meets habitat fragmentation: linking landscape and biogeographical scale levels in research and conservation. Biol Conserv 117:285-297

Parmesan C, Yohe G (2003) A globally coherent fingerprint of climate change impacts across natural systems. Nature 421:37-42

Root RB, Kareiva PM (1984) The search for resources by cabbage butterflies (Pieris rapae)—ecological consequences and adaptive significance of markovian movements in a patchy environment. Ecology 65:147-165

Root TL, Price JT, Hall KR, Schneider SH, Rosenzweig C, Pounds JA (2003) Fingerprints of global warming on wild animals and plants. Nature 421:57-60

Roy DB, Rothery P, Moss D, Pollard E, Thomas JA (2001) Butterfly numbers and weather: predicting historical trends in abundance and the future effects of climate change. J Anim Ecol 70:201-217

Schtickzelle N, Joiris A, Van Dyck H, Baguette M (2007) Quantitative analysis of changes in movement behaviour within and outside habitat in a specialist butterfly. BMC Evol Biol 7:4 
Schwartz MW, Iverson LR, Prasad AM (2001) Predicting the potential future distribution of four tree species in Ohio using current habitat availability and climatic forcing. Ecosystems 4:568-581

Settele J, Kudrna O, Harpke A, Kühn I, Van Swaay C, Verovnik R, Warren M, Wiemers M, Hanspach J, Hickler T, Kühn E, Van Halder I, Veling K, Vliegenthart A, Wynhoff I, Schweiger O (2008) Climatic risk atlas of European butterflies. Pensoft, Sofia-Moscow

Shreeve TG (1984) Habitat selection, mate location, and microclimatic constraints on the activity of the speckled wood butterfly Pararge aegeria. Oikos 42:371-377

Simmons AD, Thomas CD (2004) Changes in dispersal during species' range expansions. Am Nat 164:378-395

Thomas CD, Bodsworth EJ, Wilson RJ, Simmons AD, Davies ZG, Musche M, Conradt L (2001) Ecological and evolutionary processes at expanding range margins. Nature 411:577-581

Travis JMJ (2003) Climate change and habitat destruction: a deadly anthropogenic cocktail. Proc R Soc Lond B Biol Sci 270:467-473

Van den Hurk B, Tank AK, Lenderink G, Van Ulden A, Van Oldenborgh GJ, Katsman C, Van den Brink H, Keller F, Bessembinder J, Burgers G, Komen G, Hazeleger W, Drijfhout S (2007) New climate change scenarios for the Netherlands. Water Sci Technol 56:27-33

Van Dyck H, Baguette M (2005) Dispersal behaviour in fragmented landscapes: routine or special movements? Basic Appl Ecol 6:535-545

Van Dyck H, Matthysen E (1998) Thermoregulatory differences between phenotypes in the speckled wood butterfly: hot perchers and cold patrollers? Oecologia 114:326-334

Van Swaay CAM (2003) Butterfly densities on line transects in the Netherlands from 1990 to 2001. Entomologische Berichten 63:82-87

Van Swaay CAM, Nowicki P, Settele J, van Strien AJ (2008) Butterfly monitoring in Europe: methods, applications and perspectives. Biodivers Conserv 17:3455-3469

Vos CC, Berry PM, Opdam P, Baveco JM, Nijhof B, O’Hanley J, Bell C, Kuipers H (2008) Adapting landscapes to climate change: examples of climate-proof ecosystem networks and priority adaptation zones. J Appl Ecol 45:1722-1731

Warren MS, Hill JK, Thomas JA, Asher J, Fox R, Huntley B, Roy DB, Telfer MG, Jeffcoate S, Harding P, Jeffcoate G, Willis SG, Greatorex-Davies JN, Moss D, Thomas CD (2001) Rapid responses of British butterflies to opposing forces of climate and habitat change. Nature 414:65-69

Wickman PO (1985) The influence of temperature on the territorial and mate locating behavior of the small heath butterfly, Coenonympha pamphilus (L) (Lepidoptera, Satyridae). Behav Ecol Sociobiol 16:233-238

Zollner PA, Lima SL (1999) Search strategies for landscape-level interpatch movements. Ecology 80:1019-1030 